\title{
Systemic and immunotoxicity of pristine and PEGylated multi-walled carbon nanotubes in an intravenous 28 days repeated dose toxicity study
}

This article was published in the following Dove Press journal:

International Journal of Nanomedicine

27 February 2017

Number of times this article has been viewed

Ting Zhang ${ }^{1-3}$

Meng Tang ${ }^{1-3}$

Shanshan Zhang ${ }^{1-3}$

Yuanyuan $\mathrm{Hu}^{1-3}$

$\mathrm{Han} \mathrm{Li}^{4}$

Tao Zhang ${ }^{4}$

Yuying Xue ${ }^{1-3}$

Yuepu $\mathrm{Pu}^{1-3}$

'Key Laboratory of Environmental Medicine Engineering, Ministry of Education, School of Public Health, Southeast University, Nanjing, China; ' 2 jiangsu key Laboratory for Biomaterials and Devices, Southeast University, Nanjing, China; ${ }^{3}$ Collaborative Innovation Center of Suzhou Nano Science and Technology, Suzhou, China; ${ }^{4}$ Department of Material Science and Engineering, National Key Laboratory of Solid State Microstructures, Nanjing University, Nanjing, China
Abstract: The numerous increasing use of carbon nanotubes (CNTs) derived from nanotechnology has raised concerns about their biosafety and potential toxicity. CNTs cause immunologic dysfunction and limit the application of CNTs in biomedicine. The immunological responses induced by pristine multi-walled carbon nanotubes (p-MWCNTs) and PEGylated multi-walled carbon nanotubes (MWCNTs-PEG) on BALB/c mice via an intravenous administration were investigated. The results reflect that the p-MWCNTs induced significant increases in spleen, thymus, and lung weight. Mice treated with p-MWCNTs showed altered lymphocyte populations $\left(\mathrm{CD}^{+}, \mathrm{CD}^{+}, \mathrm{CD}^{+}\right.$, and $\left.\mathrm{CD} 19^{+}\right)$in peripheral blood and increased serum $\operatorname{IgM}$ and $\operatorname{IgG}$ levels, and splenic macrophage ultrastructure indicated mitochondria swelling. p-MWCNTs inhibited humoral and cellular immunity function and were associated with decreased immune responses against sheep erythrocytes and serum hemolysis level. Natural killer (NK) activity was not modified by two types of MWCNTs. In comparison with two types of MWCNTs, for a same dose, p-MWCNTs caused higher levels of inflammation and immunosuppression than MWCNTs-PEG. The results of immunological function suggested that after intravenous administration with p-MWCNTs caused more damage to systemic immunity than MWCNTs- PEG. Here, we demonstrated that a surface functional modification on MWCNTs reduces their immune perturbations in vivo. The chemistry-modified MWCNTs change their preferred immune response in vivo and reduce the immunotoxicity of p-MWCNTs.

Keywords: multi-walled carbon nanotubes, surface-functionalized, immunotoxicity, BALB/c mice, immunosuppression

\section{Introduction}

Carbon nanotube (CNT) applications have been increasingly used not only in materials science but also in biomedical, chemical, and electronics fields because of their unique physicochemical, mechanical, and electronic properties. ${ }^{1,2}$ Due to lack of solubility and dispersion, and the presence of metallic impurities, potential application of pristine CNTs (p-CNTs) is quite limited. ${ }^{3-5}$ In order to extend the biomedical application of CNTs, it is necessary to improve their solubility and dispersion by chemical modification, including through covalent and noncovalent functionalization methods, that make them easily soluble in water and able to enter cells, even into the deep tissue. But these strategies do not necessarily make CNTs biocompatible particularly in reducing the immune response. ${ }^{6}$ Understanding the interactions between CNTs and the immune system is also a critical issue for their safe application in medicine and pharmacy.
Correspondence: Yuepu Pu; Meng Tang Key Laboratory of Environmental Medicine and Engineering, Ministry of Education, School of Public Health, Southeast University, Collaborative Innovation Center of Suzhou Nano Science and Technology, Nanjing, China Tel +86 $2583272582 ;+862583272564$ Fax +86258327 2582

Email yppu@seu.edu.cn; tm@seu.edu.cn BY NC and incorporate the Creative Commons Attribution - Non Commercial (unported, v3.0) License (http:///reativecommons.org/licenses/by-ncl $3.0 /$ ). By accessing the work you
hereby accept the Terms. Non-commercial uses of the work are permitted without any further permission from Dove Medical Press Limited, provided the work is properly attributed. For permission 
Considering CNTs could be used as drug carries for therapy and diagnosis in systemic administration, it is extremely important to be aware of their negative effects on peripheral immune cells and immune system, which are the first line of defense and target for xenobiotic-induced toxicity. ${ }^{7}$ Due to their importance in the immune system, studies have reported the effects of CNTs on the functionality and viability of immune cells such as $\mathrm{T}$ and B lymphocytes, macrophages, dendritic cells, natural killer (NK) cells in vitro, focusing on toxicity, oxidative stress, cytokine induction, and inhibition of key functions such as phagocytosis. ${ }^{8-13}$ Pescatori et $\mathrm{al}^{8}$ showed that four types of functionalized multi-walled carbon nanotubes (f-MWCNTs) showed no cytotoxicity on Jurkat T and monocyte THP-1 cells, but three types of those f-MWCNTs activate the expression of pro-inflammatory genes in THP-1, whereas no significant activation was observed in T cells. Pristine multi-walled carbon nanotubes (p-MWCNTs) were not able to cause secretion of cytokine in peripheral blood mononuclear cells (PBMCs), but could increase TLR agonist-induced cytokine secretion and PHAinduced T-cell cytokine release by PBMC. ${ }^{3}$ In contrast to this, Delogu et $\mathrm{al}^{9}$ demonstrated that f-MWCNTs had no cytotoxicity on human monocytes and NK cells. Similarly, Dumortier et $\mathrm{al}^{12}$ found that the two types of f-MWCNTs neither decreased cellular vitality nor affected the functional activity of immunoregulatory cells. Also, Wang et al ${ }^{14}$ reported that carboxylic MWCNTs did not induce phenotypical maturation of DCs with concentrations of up to $100 \mu \mathrm{g} / \mathrm{mL}$. The results were inconsistent, which is to be expected on the basis of the different types of CNTs used in vitro studies.

As in the case of immune cell experiments, in vivo studies on CNTs are too limited to draw any general systematic conclusions, and again the CNTs come from the different sources and synthesis methods, which makes it difficult to compare results from different studies. In the previous studies, p-MWCNTs have been shown to activate the monocytes or macrophages and induce pro-inflammatory cytokine secretion inflammation, which resulted in an increase in the immune response of nanotubes. ${ }^{15,16}$ Similarly, the same sequence of research reported increases of pro-inflammatory cytokines and the allergy-like response detected by mice after intratracheal instillation of non-functionalized MWCNTs. ${ }^{17}$ Meanwhile, it was also reported that MWCNTs could lead to systemic immune suppression in mice after whole-body inhalation, ${ }^{18}$ and then the researchers demonstrated that MWCNTs could induce suppression of systemic immunity through activation of the cyclooxygenase pathway. ${ }^{19}$ As well, the relevance of findings has reported that the induction of immune responses and toxicity by CNTs mainly depend on their physicochemical properties and route of exposure. ${ }^{6,7}$ In spite of the increasing experimental data on the immune effects of CNTs, at present, there are a few studies focusing on the systemic immunotoxicity effects of different types of MWCNTs after intravenous administration, especially on the immune organs and immune function.

As previously described, p-MWCNTs entered the cells both actively and passively through the cell membrane, then nanotubes were clustered around the phagosomes and entered the nucleus, and resulted in oxidative stress and cell death of human macrophages. ${ }^{20}$ Strategies for surface modification have recently increased in popularity, especially modifications with small molecular compounds and polymers are generally considered more biocompatible than p-CNTs due to improved water-soluble and dispersion properties in biological media. ${ }^{21}$ Previous studies have reported that carboxylated, ${ }^{22}$ amino-coated, ${ }^{23}$ taurine-, polystyrene-, and poly(ethylene glycol)-functionalized $\mathrm{CNTs}^{24}$ showed lower cytotoxicity and induced less cytokine release, pulmonary inflammation, oxidative stress, and fibrosis than p-CNTs. Their conclusions were consistent with the results that surface modification is one of the primary determinants of CNT toxicity effects. With extensive biomedical applications, large variety of surface-modified CNTs should be systematically evaluated in toxic effects in vivo, especially in immunotoxicity. Furthermore, other factors influence the toxicity effects of MWCNTs and have the potential to modulate their biological effects, such as their sizes, ${ }^{25}$ lengths,${ }^{26}$ and contamination with metal catalysts. ${ }^{27}$ Several data indicate that length is one of the most important determinants for toxicity of CNTs and it is unclear whether the length of MWCNTs affects the outcome of immunotoxicity, which is one of the concerns in our study. Therefore, there is an extreme need for a better understanding of the relationship between the different functionalizations of MWCNTs and immune system.

In this study, we compared the toxicity after repeated administration of two types of MWCNTs (p-MWCNTs and PEGylated multi-walled carbon nanotubes [MWCNTsPEG]) in mice for 4 weeks (once a week) by investigating the relationship between the characterization on MWCNTs and their potential systemic immunotoxicity. The immunotoxicity of MWCNTs could be detected using parameters of the immune system such as described in OECD 407 guideline. Special emphasis was on the effects of the spleen as part of the immune system as our previous results showed accumulation of MWCNTs in the spleen. ${ }^{28,29}$ 


\section{Materials and methods \\ Preparation and characterization of f-MWCNTs}

The p-MWCNTs obtained as powder from Shenzhen Nano harbor Co. had an average diameter ranging from 10 to $20 \mathrm{~nm}$, a length range of $5-15 \mu \mathrm{m}$, and a purity of $>95 \%$. In the first step, we used p-MWCNTs to prepare carboxyl ( $\mathrm{COOH}$ )-functionalized MWCNTs via oxidization. Then the PEG modification was introduced by esterification of the acylated $\mathrm{COOH}-\mathrm{MWCNTs}$ with polyethylene glycol. The characterization of two types of MWCNTs (p-MWCNTs and MWCNTs-PEG) was completed using procedures previously described ${ }^{30}$ (see the details in Supplementary materials, 'Characterization of MWCNTs' section). For the experiments, samples (p-MWCNTs and MWCNTs-PEG) were diluted to the appropriate concentration with phosphate buffer containing $0.5 \%$ Tween- 80 (PBST). Nanotube suspensions were characterized using dynamic light scattering (DLS) and zeta potential measurements (Zetasizer Nano ZS90; Malvern Instruments, Worcestershire, UK). The endotoxin content was determined by ToxinSensor ${ }^{\mathrm{TM}}$ Chromogenic LAL Endotoxin Assay Kit (GenScript; Nanjing, China, detection limit 0.005 EU/mL).

\section{Animals}

Seven-week-old female BALB/c mice were provided by Yangzhou University Comparative Medicine Center. Animals were bred under SPF conditions and barrier maintained during the experiment. They were maintained in animal care facilities, fully accredited by the China Food and Drug Administration, in a temperature-regulated room (temperature of $22^{\circ} \mathrm{C} \pm 1{ }^{\circ} \mathrm{C}$, humidity of $60 \% \pm 10 \%$, and light/dark cycle of $12 \mathrm{~h} / 12 \mathrm{~h}$ ) for 5 days prior to the study. The nutritionally complete laboratory food and water were provided ad libitum. All of the protocols were approved by the Ethics Committee of Animal Experiments of the Southeast University, and the animal study was carried out in accordance with the Ethical Guidelines for Animal Use and Care established by Southeast University (Nanjing, China). All the surgeries were performed under sodium pentobarbital anesthesia, and all efforts were made to minimize suffering.

\section{Experimental design}

The present study was performed according to the general principles of OECD guideline 407 (Repeated dose 28-day oral study in rodents) with some adjustments. The mice were administrated p-MWCNTs and MWCNTs-PEG via intravenous injection. BALB/c female mice were randomly divided into three groups according to weight, and each group was further divided into five subgroups ( $\mathrm{n}=6$ for each subgroup). The mice were intravenously injected (tail vein) once a week for 28 days. In single injection, vehicle control (PBST), $0.02 \mathrm{mg} / \mathrm{kg} \cdot \mathrm{bw}, 0.1 \mathrm{mg} / \mathrm{kg} \cdot \mathrm{bw}, 0.5 \mathrm{mg} / \mathrm{kg} \cdot \mathrm{bw}$ of p-MWCNTs, and $0.1 \mathrm{mg} / \mathrm{kg} \cdot \mathrm{bw}$ of MWCNTs-PEG were given to each mouse in each subgroup, respectively. Dosage and time points in the all experiments are summarized in Table S1. Mice were weighed prior to and weekly during the experiment. Individual body weights were used to calculate the individual dose levels.

\section{Measurement of organ indexes}

At 7 days after the last injection, body weight of mice was measured and the mice were sacrificed by cervical dislocation. The liver, lung, spleen, and thymus were grossly observed and removed immediately. The absolute organ weight was measured and then relative organ weight ( $\%$ of body weight) was calculated.

\section{Histopathology}

At 7 days after the last injection, the mice in group 1 were sacrificed. After collecting blood, the mice were evaluated macroscopically for gross lesions. The following organs were examined and sampled: spleen, lymph nodes (mesenteric and inguinal), thymus, lung, heart, liver, and kidney. All tissue samples were fixed in $4 \%$ neutral buffered formaldehyde (10\% formalin) and routinely processed (hematoxylin and eosin staining $[\mathrm{H} \& \mathrm{E}])$ for histopathology.

\section{Spleen observation by transmission electron microscopy (TEM)}

The spleen was harvested immediately after removing the organ and cut into $1-2 \mathrm{~mm}^{3}$ cubes, immersed in $2.5 \%$ glutaraldehyde at $4^{\circ} \mathrm{C}$. After washing several times with phosphatebuffered saline (PBS), they were fixed with $1 \%$ osmium tetroxide, dehydrated with serial alcohol, embedded in Epon 812 , and polymerized for 24 hours at $37^{\circ} \mathrm{C}$. The blocks were trimmed for cutting semi-thin and ultrathin sections with a LKB-V ultramicrotome (LKB, Stockholm, Sweden). Semithin (1 mm thick) sections were stained with $1 \%$ toluidine blue at $40^{\circ} \mathrm{C}-50^{\circ} \mathrm{C}$, washed, and dried. Ultrathin sections stained with uranyl acetate and lead citrate were examined under JEM 1010 electron microscope (JEOL, Peabody, MA, USA) at an accelerating voltage of $80 \mathrm{kV}$.

\section{Hematology}

Hematology and clinical chemistry parameters were measured by extracting the eyeball blood. Hematological parameters 
included white blood cell (WBC) count, neutrophil percentage (NEUT\%), lymphocyte percentage (LYM\%), eosinophil percentage (EOS\%), basophil percentage (BASO $\%$ ), and monocyte percentage. All hematology parameters in the blood samples were determined in XT-4000i Hematology Analyzer (Sysmex, Kobe, Japan).

\section{Clinical chemistry}

After collection of blood serum and storage at $20^{\circ} \mathrm{C}$, the serum samples were characterized on a Biochemical Autoanalyzer (Type 7170; Hitachi, Tokyo, Japan) by using following clinical chemical parameters: albumin, alkaline phosphatase (ALP), alanine aminotransferase (ALT), aspartate aminotransferase (AST), lactate dehydrogenase (LDH), glucose, urea nitrogen (BUN), creatinine (CRE), cholesterol, triglyceride, and total protein.

\section{Peripheral blood lymphocyte phenotype}

Phenotypic analyses of blood lymphocytes were analyzed by fluorescence-activated cell sorting (FACS). Briefly, the cells were incubated with PE or FITC-conjugated monoclonal antibodies (Panel 1: Anti-CD3 [FITC], Anti-CD4 [PE], or Anti-CD8 [PE-Cy5-CD8]; Panel 2: Anti-CD19 [FITC], Anti-CD49 [PE]) for 15 minutes, washed three times, and then resuspended in $50 \mathrm{PBS} \mu \mathrm{L}$ before determination. At least 10,000 cells were analyzed using a FACScan flow cytometer using CellQuest software (Becton Dickinson, San Jose, CA, USA), and data were expressed as mean fluorescence intensity for a given molecule per cell.

\section{Immunoglobulins}

After collection of blood serum and storage at $20^{\circ} \mathrm{C}$, immunoglobulin levels were determined in an enzyme-linked immunosorbent assay (R\&D Systems, Minneapolis, MN, USA) using mouse monoclonal antibodies against mice IgG and IgM, respectively.

\section{Determination of immune parameters Measuring the primary immune response}

Twenty-four days after first administration, the mice in group 2 were immunized by $0.2 \mathrm{~mL} 2 \%$ sheep red blood cells $(\mathrm{SRBC})(\mathrm{v} / \mathrm{v})$ via intraperitoneal injection. On the last day $(\mathrm{t}=28 \mathrm{~d})$, the mice were sacrificed, and the target tissue spleens were collected aseptically. The suspension of splenic cells was prepared by methods as described in the study by Ladics. ${ }^{31}$ Further details of the method are described in the studies by Ladics ${ }^{31}$ and Huang et al. ${ }^{32}$ The results were expressed as plaque-forming cells (PFC) number $/ 10^{6}$ cells.

\section{Mitogen-stimulated lymphocyte proliferation}

The mitogen-stimulated lymphocyte proliferations were detected with isolated splenocytes. Spleen single-cell suspensions $\left(100 \mu \mathrm{L} ; 2 \times 10^{6}\right.$ cells $\left./ \mathrm{mL}\right)$ were seeded in triplicates in a 96-well plate. Then $100 \mu \mathrm{L}$ of RPMI growth medium containing $50 \mu \mathrm{g} / \mathrm{mL}$ of the mitogen concanavalin A (ConA) or $20 \mu \mathrm{g} / \mathrm{mL}$ lipopolysaccharides (LPS) (Sigma-Aldrich, St Louis, MO, USA) was added in duplicate wells. For control, $100 \mu \mathrm{L}$ of growth medium was added in duplicate wells. The plate was incubated for 72 hours at $37^{\circ} \mathrm{C}$ in a humidified chamber with $5 \% \mathrm{CO}_{2}$. Then, $10 \mu \mathrm{L}$ of CCK-8 solution was added to each well and further incubated at $37^{\circ} \mathrm{C}$ for 4 hours. Finally, the optical density (OD) value was measured by a microplate reader set to $450 \mathrm{~nm}$. Stimulation index (SI) was calculated using the following formula:

$$
\mathrm{SI}=\frac{\mathrm{OD}_{\text {stimulated culture }}-\mathrm{OD}_{\text {unstimulated culture }}}{\mathrm{OD}_{\text {unstimulated culture }}}
$$

\section{Measurement of serum hemolysin level}

The mice in group 2 were immunized by SRBC as already described. On the last day ( $\mathrm{t}=28 \mathrm{~d})$, blood was collected from the angular vein before the mice were sacrificed. Further details of the method are described in the studies by Huang et $\mathrm{al}^{32}$ and Costabile. ${ }^{33}$ The OD was measured at $540 \mathrm{~nm}$. The half value of hemolysis (HC50) was calculated as follows:

$$
\begin{aligned}
& \text { Sample HC50 } \\
& \qquad=\frac{\mathrm{OD}_{\text {sample }}-\mathrm{OD}_{\text {blank }}}{\mathrm{OD}_{\text {half SRBC hemolysis }}-\mathrm{OD}_{\text {blank }}} * \text { Dilution index. }
\end{aligned}
$$

\section{NK cell activity}

Spontaneous cytotoxicity of spleen cell populations was evaluated by $\mathrm{LDH}$ releasing assay for determination of NK cell activity. Spleen single-cell suspensions (100 $\mu \mathrm{L}$; $1 \times 10^{5}$ cells $/ \mathrm{mL}$ ) were seeded in triplicates in a 96-well plate. Maloney virus-induced mouse lymphoma cell line (YAC-1) was maintained in continuous culture and used as target cells in NK activity assays. Further details of the method are described in the study by Huang et al. ${ }^{32}$ The OD was measured at $490 \mathrm{~nm}$. NK cell activity was calculated and transformed as follows:

$$
\begin{aligned}
& \text { NK cell activity }(\%) \\
& =\frac{\mathrm{OD}_{\text {sample }}-\mathrm{OD}_{\text {target cell spontaneous release }}}{O D_{\text {target cell maximum release }}-\mathrm{OD}_{\text {target cell spontaneous release }}} * 100 \%
\end{aligned}
$$


Table I Physicochemical characterization of the MWCNTs

\begin{tabular}{lll}
\hline Characterization & $\begin{array}{l}\text { Pristine } \\
\text { MWCNTs }\end{array}$ & $\begin{array}{l}\text { MWCNTs- } \\
\text { PEG }\end{array}$ \\
\hline Length $(\mu \mathrm{m})$ & $\sim 5-15$ & $\sim 0.3-0.6$ \\
Diameter $(\mathrm{nm})$ & $\sim 10-20$ & $\sim 10-20$ \\
$\begin{array}{l}\text { Zeta potential }(\mathrm{mV} \text { in phosphate } \\
\text { buffer containing 0.5\% Tween-80) }\end{array}$ & -15.5 & -12.8 \\
Impurities (wt\%) & 98.9429 & 99.0226 \\
\hline
\end{tabular}

Abbreviations: MWCNTs, multi-walled carbon nanotubes; MWCNTs-PEG, PEGylated multi-walled carbon nanotubes.

\section{Statistical analysis}

All data were expressed as the mean \pm standard deviation. The results were compared by one-way analysis of variance followed by Dunnett's test for comparison of treatment groups to the negative control group and LSD test for pairwise comparisons among treatment groups. A value of $P<0.05$ was considered as statistically significant.

\section{Results}

\section{Characterization of two types of MWCNTs}

After comprehensive characterization of the two types of MWCNTs was performed using Fourier transform infrared spectroscopy, it was validated with thermogravimetric analysis, TEM, inductively coupled plasma mass spectrometry, and DLS methods, which provided information on the chemical modification, morphological shape, and chemical composition of nanotubes as observed in our previous studies $^{30,34}$ (Figures S1 and S2). Prior to the study of the toxicity, the two types of MWCNTs were characterized based on size distribution, zeta potentials, and chemical composition of the nanotubes (Table 1). It was worth noting that the TEM examinations (Figure 1) indicated that the length of MWCNTs-PEG was shortened to 300-600 nm, which indicated that the length of the MWCNTs-PEG becomes much shorter during the synthesis process. In the two types of MWCNTs, no (or at least lower than the detection limit) endotoxin contamination was measured in the endpoint chromogenic LAL assay (data not shown).

\section{Macroscopic evaluation and effect on body weights}

There were no clinical signs for toxicity during the 28-day exposure period for treatment with either p-MWCNTs or MWCNTs-PEG. The body weight analysis show that the treatments groups did not differ statistically significantly in the dose-related changes (Table S2).

\section{Specific organ gross observation and effect on organ coefficient}

Gross observation of the mice revealed enlarged brownish colored lungs, spleens, and livers, and enlarged, edematous, and congested lymph nodes (Figure 2). MWCNTs are mainly deposited in the lungs, liver, and spleen. Some findings such as hypertrophy and congestive of inguinal lymph nodes (Figure 2A), congestion spots of lung (Figure 2B), congestive and edematous changes of liver (Figure 2C), or spleen atrophy (Figure 2D) were observed in the highest dose groups of p-MWCNTs treatment. Significant changes on the gross findings of specific organs were observed in high dosing of the p-MWCNT group compared to that of the control group.

The organ weight/body weight coefficient of the heart, kidneys, brain, testes, and epididymis showed no differences in the different dose groups compared to the control group (data not shown), whereas an increase in organ weight/body weight coefficient of the lung, liver, spleen, and thymus was observed (Figure 3). There were
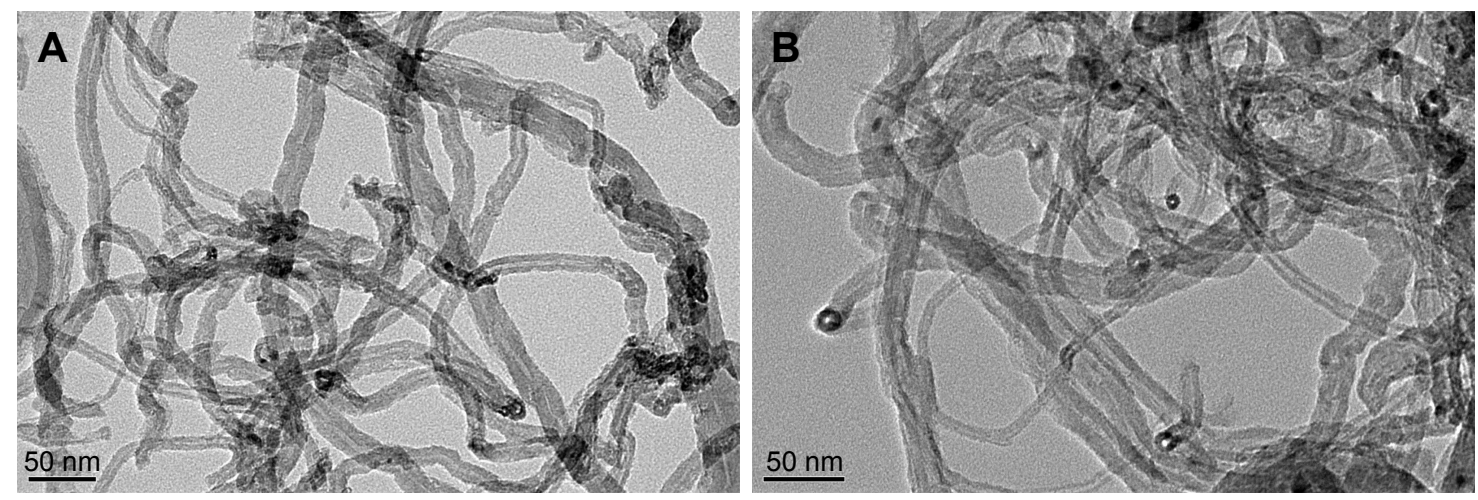

Figure I Transmission electron microscopy image of pristine and functionalized MWCNTs.

Notes: (A) p-MWCNTs and (B) MWCNTs-PEG.

Abbreviations: p-MWCNTs, pristine multi-walled carbon nanotubes; MWCNTs-PEG, PEGylated multi-walled carbon nanotubes. 


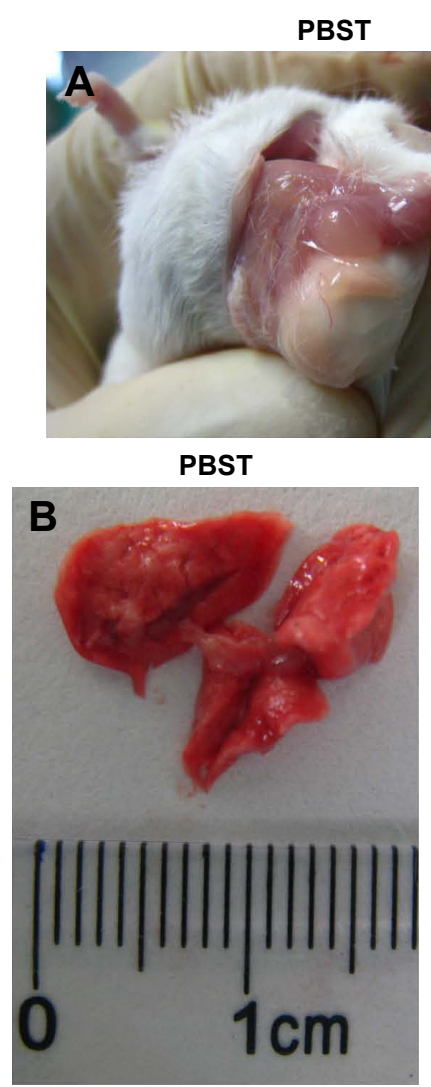

PBST

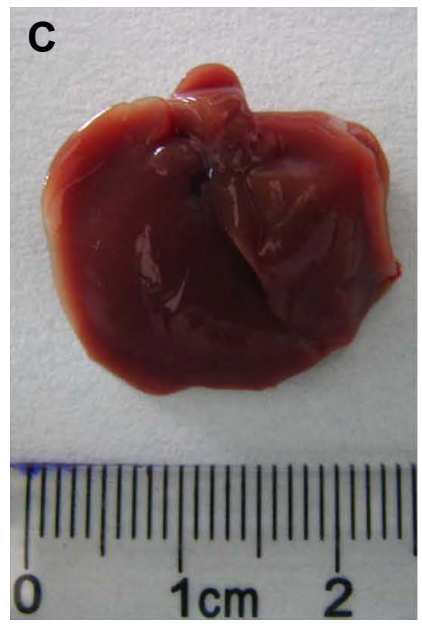

PBST

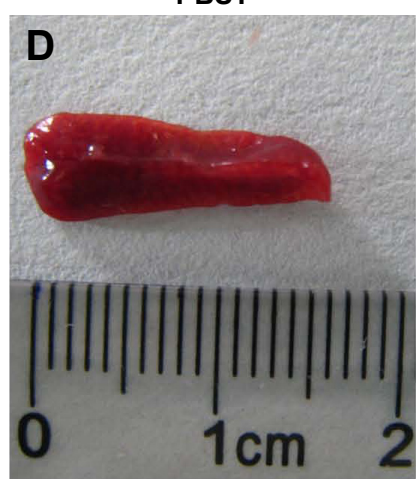

MWCNTS-PEG

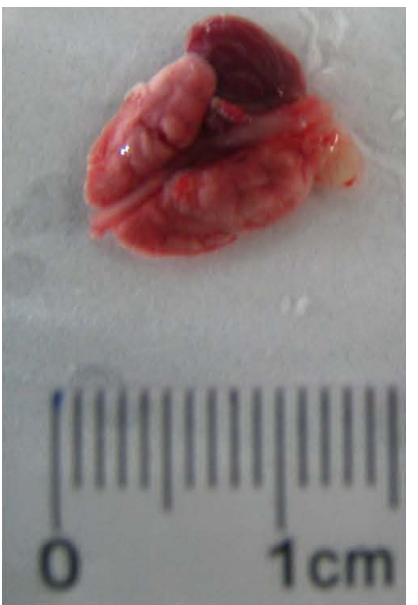

MWCNTs-PEG

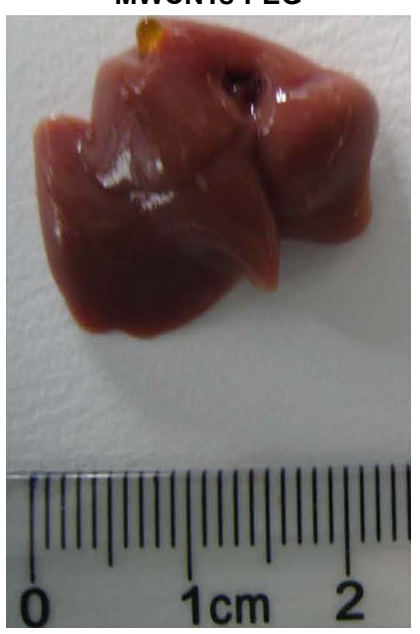

MWCNTS-PEG

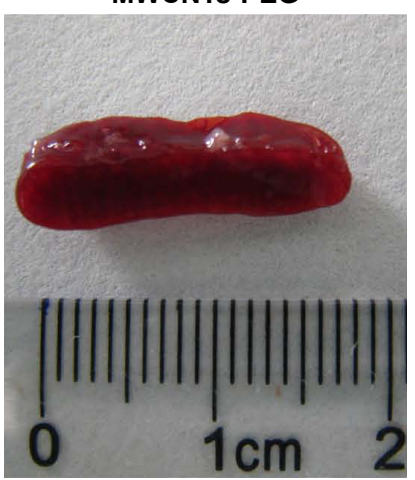

Pristine MWCNTs

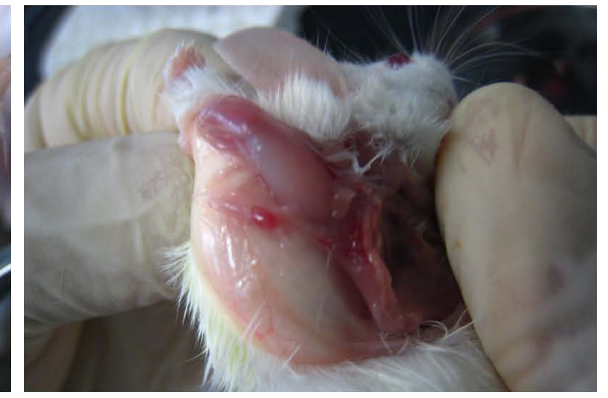

Pristine MWCNTs

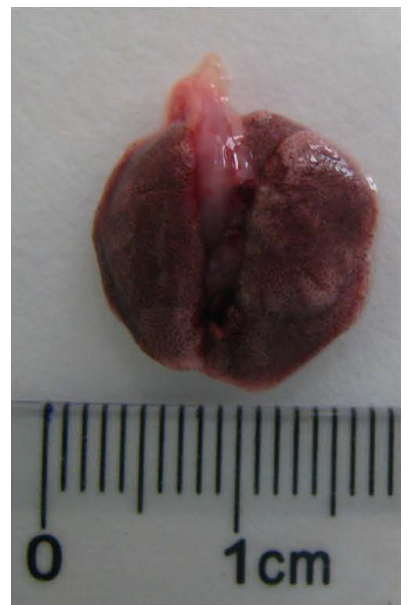

Pristine MWCNTs

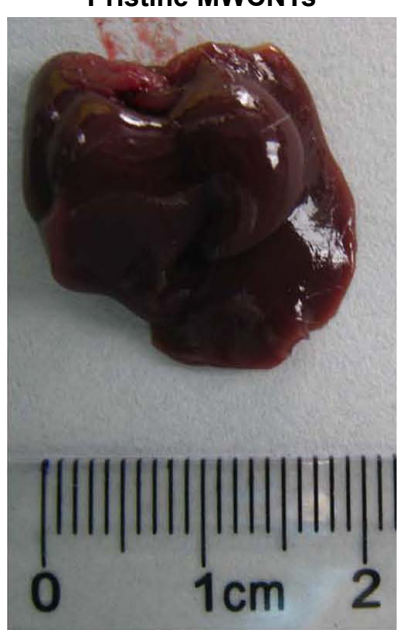

Pristine MWCNTs

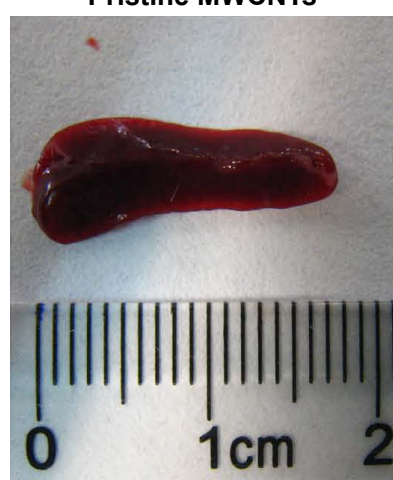

Figure 2 Gross observation of hypertrophy of inguinal lymph nodes (A), and congestive and edematous changes of the lung (B), liver (C), and spleen (D).

Abbreviations: PBST, phosphate buffer containing 0.5\% Tween-80; MWCNTs-PEG, PEGylated multi-walled carbon nanotubes; MWCNTs, multi-walled carbon nanotubes. 


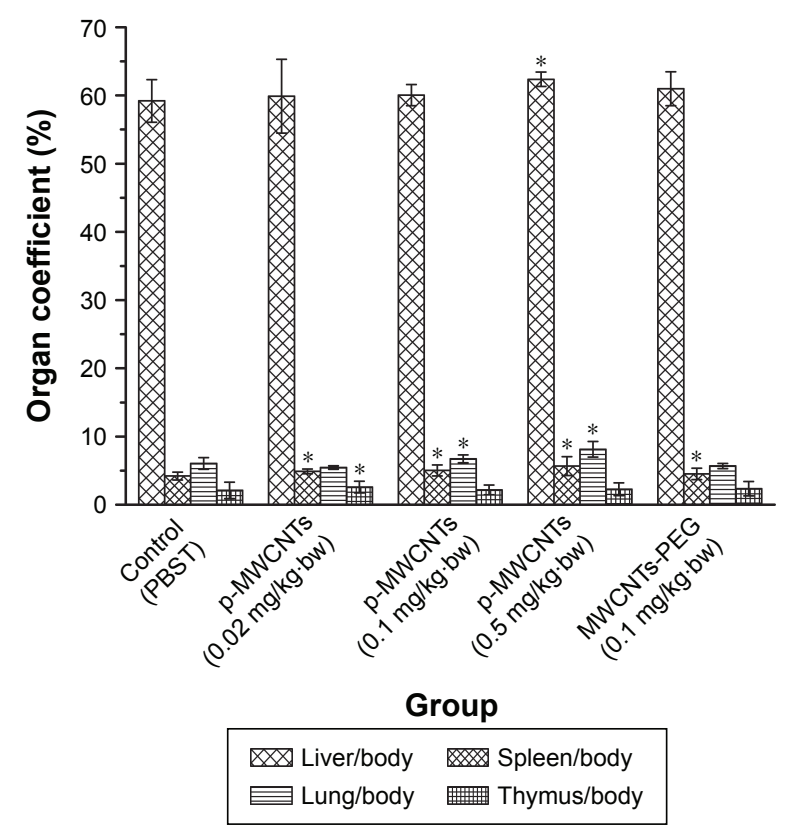

Figure 3 Organ coefficient of mice after 28 days of intravenous treatment with P-MWCNTs and MWCNTs-PEG.

Notes: Data represent the mean $\pm S D$ of six mice. *Values significantly different from control results $(P<0.05)$.

Abbreviations: p-MWCNTs, pristine multi-walled carbon nanotubes; MWCNTsPEG, PEGylated multi-walled carbon nanotubes; SD, standard deviation; PBST, phosphate buffer containing $0.5 \%$ Tween- 80 . significant $(P<0.05)$ dose-related increases in the relative spleen weights of $\mathrm{p}$-MWCNTs, and a significant increase $(P<0.05)$ spleen weight after treated with $0.1 \mathrm{mg} / \mathrm{kg} \cdot \mathrm{bw}$ MWCNTs-PEG.

\section{Histopathology}

The intravenously injected MWCNTs should be regarded as exogenous particles, which were recognized by the immune system. Macrophage is a type of phagocyte and plays a role in alerting the immune system of the presence of particulate antigens, especially in injection site. Therefore, we investigated whether the injected MWCNTs were engulfed by macrophages around the tail vein through histochemical observations. Figure 4A presents the H\&E section that massive p-MWCNTs deposition was observed in the tail vein of the injection site and numerous cells became black after 28 days of engulfing the injected p-MWCNTs. Since macrophages are relatively large cells and could accommodate particulates, the observed black cells could be distinguished histologically as mainly macrophages. The results indicated that the intravenous injected p-MWCNTs were swiftly engulfed by macrophages in situ. This also implied

\section{A}
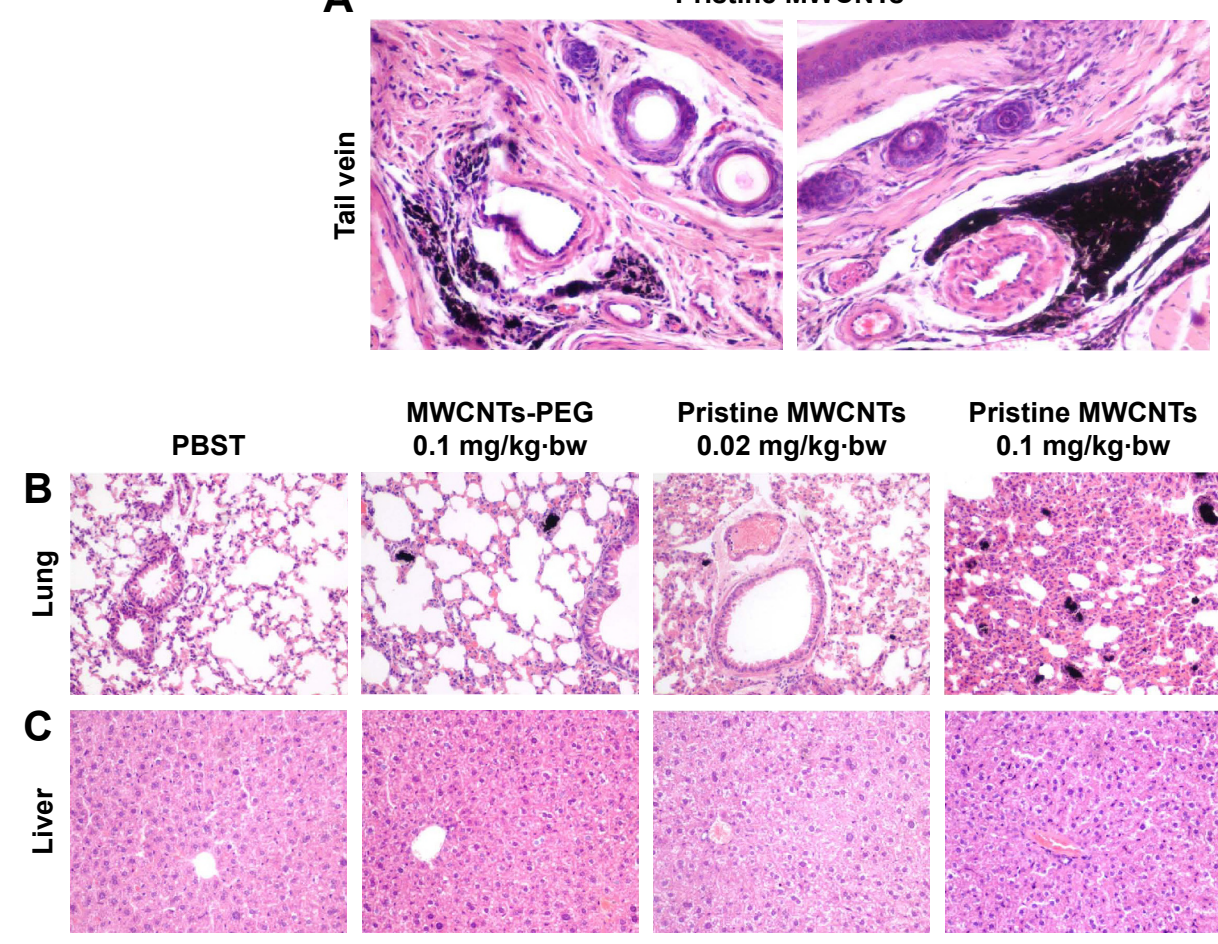

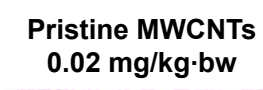

$0.02 \mathrm{mg} / \mathrm{kg} \cdot \mathrm{bw}$
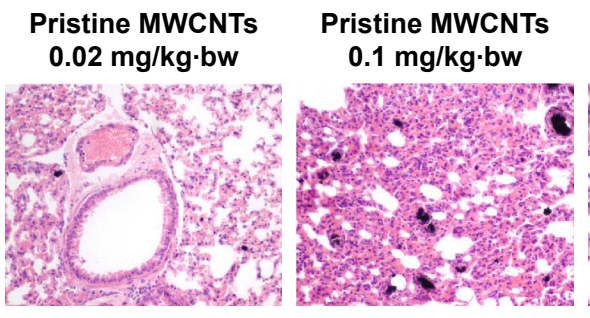

\section{Pristine MWCNTs $0.5 \mathrm{mg} / \mathrm{kg} \cdot \mathrm{bw}$}
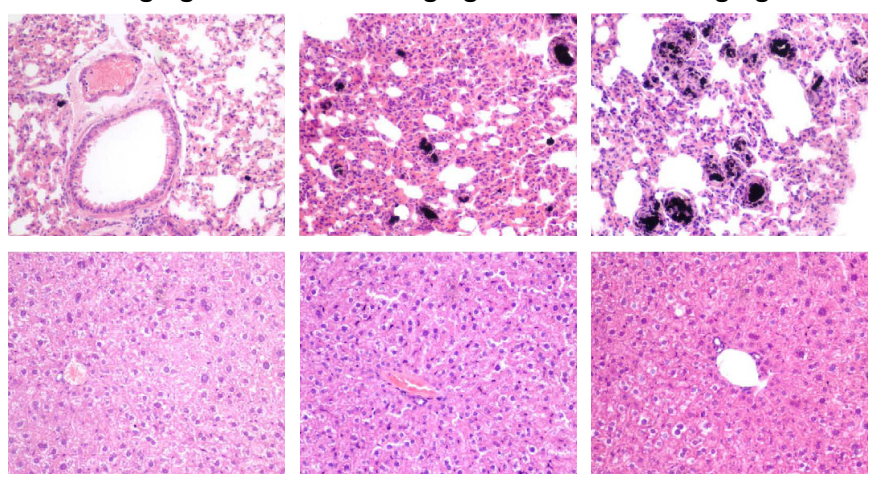

Figure 4 Microscopic images showing the histopathological changes in tissues samples (with a magnification of expansion $\times 200$ ).

Notes: (A) p-MWCNTs aggregated in the tail vein of the injection site and numerous cells became black after engulfing the injected MWCNTs; (B) lung pathological lesions in a dose-dependent manner after intravenous administration of high and medium doses of p-MWCNTs; (C) livers showed some loss of sinusoid space and hydropic degeneration with minor fatty change at the highest p-MWCNTs concentration.

Abbreviations: p-MWCNTs, pristine multi-walled carbon nanotubes; MWCNTs, multi-walled carbon nanotubes; PBST, phosphate buffer containing $0.5 \%$ Tween-80. 
that the macrophage cells had been activated to exhibit their phagocytosis function.

Histopathological observation indicated that intravenous administration of high and medium doses of p-MWCNTs and MWCNTs-PEG could induce pathological changes in a dose-dependent manner (Figure 4B). Some neutrophil infiltration and alveolar septal thickening were observed in lung tissues. The liver histopathological pictures showed the structural disorder of liver lobules and some loss of sinusoid space (Figure 4C). Livers of mice in the p-MWCNT group exhibited mild vacuolar degeneration of hepatocytes, no obvious necrotic cell, and mild sinusoidal congestion, mainly at the highest p-MWCNT concentration. Individual liver cells were found, which indicated that a small amount of CNTs deposited in the interstitial cells.

In summary, the results show that p-MWCNT treatment could cause different degrees of pathological injury in the lung, liver, and tail vein of the injection site. However, no obvious pathological changes were found in the spleen and lymph nodes of MWCNTs-PEG-treated mice (data not shown).

\section{TEM ultrastructural images of splenocyte}

The ultrastructural observation of splenic lymphocyte and splenic macrophages is presented in Figure 5. It was observed that the mouse splenocyte of the control group contained round nucleus with evenly distributed euchromatin; the ultrastructure of splenic macrophages from the $0.5 \mathrm{mg} / \mathrm{kg} \cdot \mathrm{bw}$ p-MWCNT group indicate mitochondria swelling, irregular shape of nucleus, chromatin condensation, and vacuolization in splenocyte, whereas splenic macrophages treated with MWCNTs-PEG have not changed appreciably. Additionally, TEM confirmed the internalization of p-MWCNTs inside the splenic macrophages, visualized as high electronic density. The results suggested that higher dose p-MWCNTs could cause splenocyte macrophage necrosis of mice.

\section{Hematology and clinical chemistry}

Significant changes in the hematology parameters were observed after intravenous administration of MWNCTs (Table 2). p-MWCNTs and MWCNTs-PEG significantly decreased the WBC count in all the treated groups, most significantly in the $0.5 \mathrm{mg} / \mathrm{kg} \cdot \mathrm{bw}$ p-MWCNT group. When
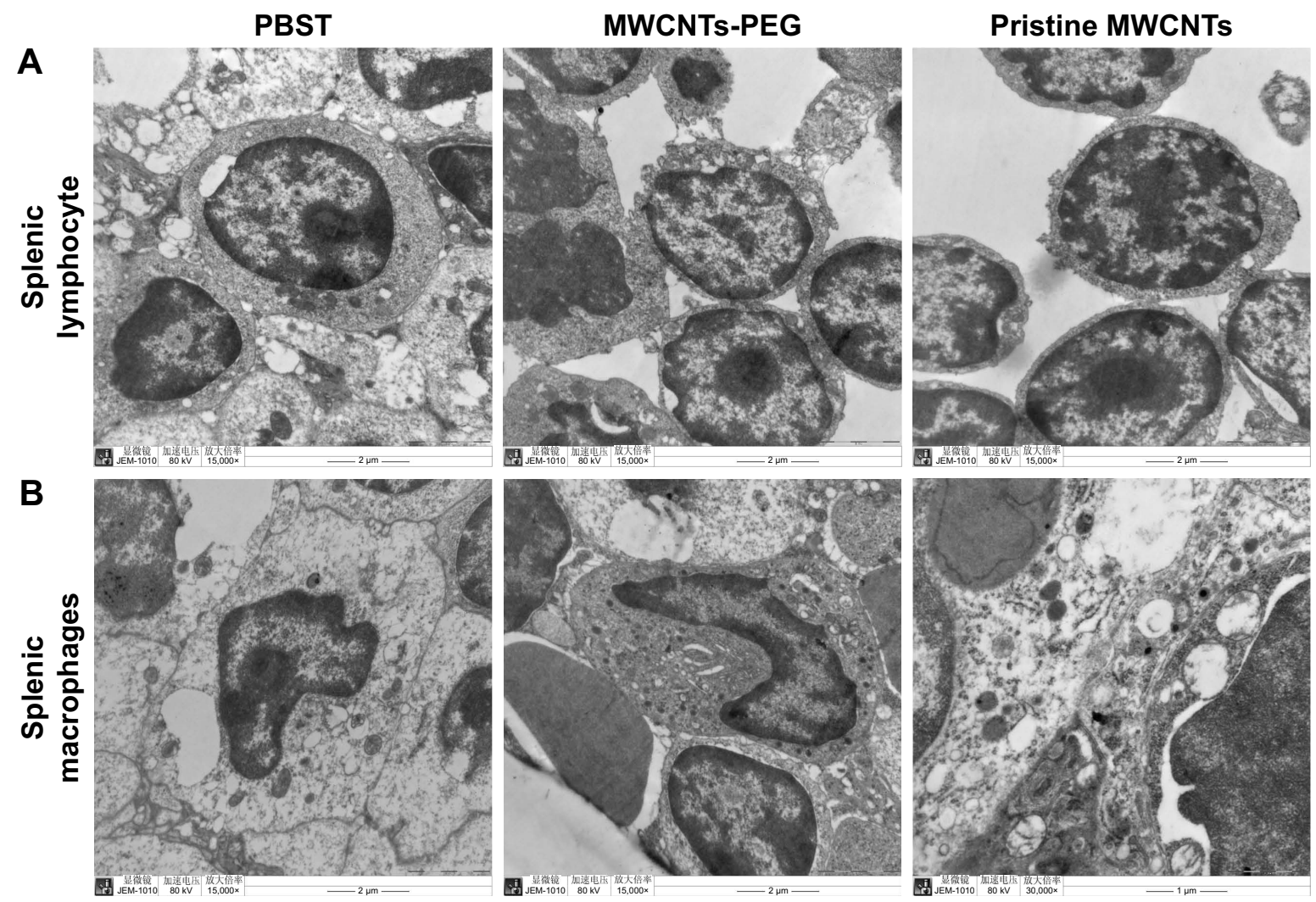

Figure 5 Transmission electron microscope micrographs from the spleen after two types of MWCNTs administration and the control group.

Notes: Splenocyte in the control group contained round nucleus with homogeneous chromatin (A); splenocyte from the $0.5 \mathrm{mg} / \mathrm{kg} \mathrm{P}-\mathrm{MWCNT}$ group indicates mitochondria swelling (B), such as nucleus chromatin condensation and vacuolization in splenocyte. Details of the macrophage cytoplasm showing internalized MWCNT are presented in image. Abbreviations: p-MWCNTs, pristine multi-walled carbon nanotubes; MWCNTs, multi-walled carbon nanotubes; PBST, phosphate buffer containing $0.5 \%$ Tween-80. 
Table 2 Hematological analysis of mice after 28 days of intravenous treatment with p-MWCNTs and MWCNTs-PEG

\begin{tabular}{llllllll}
\hline Group & Dose (mg/kg.bw) & WBC & NEUT\% & LYM\% & MON\% & EOS\% & BASO\% \\
\hline Control (PBST) & 0 & $4.5 I \pm 0.60$ & $23.38 \pm 2.57$ & $75.49 \pm 2.67$ & $0.91 \pm 0.69$ & $0.17 \pm 0.24$ & $0.24 \pm 0.13$ \\
P-MWCNTs & 0.02 & $3.71 \pm 0.33^{*}$ & $24.11 \pm 4.14$ & $74.51 \pm 4.32$ & $1.17 \pm 0.39$ & $0.14 \pm 0.24$ & $0.27 \pm 0.12$ \\
& 0.1 & $3.45 \pm 1.54^{*}$ & $24.22 \pm 4.43$ & $74.79 \pm 4.59$ & $0.67 \pm 0.24$ & $0.10 \pm 0.16$ & $0.32 \pm 0.22^{*}$ \\
& 0.5 & $3.33 \pm 0.03^{*}$ & $19.76 \pm 4.53^{*}$ & $79.12 \pm 4.55^{*}$ & $0.79 \pm 0.62$ & $0.03 \pm 0.02^{*}$ & $0.49 \pm 0.17^{*}$ \\
MWCNTs-PEG & 0.1 & $3.29 \pm 0.69^{*}$ & $21.14 \pm 3.26$ & $77.74 \pm 2.99$ & $0.86 \pm 0.50$ & $0.13 \pm 0.02^{\#}$ & $0.41 \pm 0.08^{*}$ \\
\hline
\end{tabular}

Notes: $* P<0.05$ compared to control; ${ }^{*} P<0.05$ for comparing $p-M W C N T s$ with MWCNTs-PEG.

Abbreviations: p-MWCNTs, pristine multi-walled carbon nanotubes; MWCNTs-PEG, PEGylated multi-walled carbon nanotubes; WBC, white blood cell; NEUT\%, neutrophil percentage; LYM\%, lymphocyte percentage; MON\%, monocyte percentage; EOS\%, eosinophil percentage; BASO\%, basophil percentage; PBST, phosphate buffer containing $0.5 \%$ Tween- 80 .

compared with the control group, LYM\% and BASO $\%$ were increased in the p-MWCNT group, whereas the NEUT $\%$ and EOS\% in the $0.5 \mathrm{mg} / \mathrm{kg} \cdot \mathrm{bw}$ group were significantly reduced.

In general, minor alterations were observed in clinical chemistry parameters. Several clinical chemistry parameters showed a dose-related effect including ALP, ALT, and AST (Tables 3 and 4). The increased ALP, ALT, and AST are indicative for liver damage. The renal function parameters (CRE and BUN) were not significantly different between any dose group and controls.

\section{Effect of MWCNTs on the lymphocyte and $T$ lymphocyte subsets activity in mice peripheral blood}

The changes in lymphocyte subpopulations in mice caused by intravenous administration with different doses of MWCNTs for 28 days are shown in Table 5. According to the results, the total $\mathrm{T}\left(\mathrm{CD}^{+}\right)$and total $\mathrm{B}\left(\mathrm{CD} 19^{+}\right)$caused by $0.5 \mathrm{mg} / \mathrm{kg} \cdot$ bw p-MWCNTs and the $\mathrm{CD}^{+}{ }^{+} \mathrm{T}$ lymphocytes caused by 0.1 and $0.5 \mathrm{mg} / \mathrm{kg} \cdot \mathrm{bw}$ were significantly decreased compared with those of control $(P<0.05)$. In addition, the ratio of $\mathrm{CD}^{+}$to $\mathrm{CD}^{+}\left(\mathrm{CD}^{+} / \mathrm{CD}^{+}\right)$of the $0.5 \mathrm{mg} / \mathrm{kg} \cdot \mathrm{bw}$ group was significantly lower than that of the control group $(P<0.05)$. There were no statistically significant differences between the groups for absolute cell numbers for $\mathrm{CD}^{+}$and $\mathrm{NK}\left(\mathrm{CD} 49^{+}\right)$cell subsets after administration. This increase in cell numbers can be considered responsible for the weight increase of the spleen.

\section{Immunoglobulin production in serum}

In order to evaluate the systemic immune response, the serum IgM and IgG antibody level was observed after administration of p-MWCNTs and MWCNTs-PEG. IgM and IgG are present in the blood and can bind to various pathogens and protect the body against them through agglutination and immobilization, complement activation (classical pathway), and neutralization of their toxins. As shown in Figure 6, compared to the control group, a significantly increasing level of IgM and IgG was detected in p-MWCNTs-treated mice at doses of 0.1 and $0.5 \mathrm{mg} / \mathrm{kg} \cdot \mathrm{bw}(P<0.05)$. However, a comparable concentration of IgM and IgG antibodies level showed changes in MWCNTs-PEG-treated mice.

\section{Effect of MWCNTs on mice immune function}

The PFC assay and hemolysis test were generally used to evaluate humoral immunity, the mitogen-stimulated splenocyte proliferation was commonly used to detect cellular immunity, and NK cell activity was usually used to detect non-specific immunity responses. After 28 days of administration, the high dose of p-MWCNTs $(0.5 \mathrm{mg} / \mathrm{kg} \cdot \mathrm{bw})$ induced a significant reduction in $\mathrm{PFC} / 10^{6}$ splenocytes, $\mathrm{HC} 50$, ConA-induced splenocyte proliferation, and LPS-induced

Table 3 Clinical chemistry of mice after 28 days of intravenous treatment with p-MWCNTs and MWCNTs-PEG

\begin{tabular}{|c|c|c|c|c|c|c|c|}
\hline Group & Dose $(\mathrm{mg} / \mathrm{kg} \cdot \mathrm{bw})$ & LDH (U/L) & ALT (U/L) & AST (U/L) & ALP (U/L) & TP (g/L) & ALB (g/L) \\
\hline Control (PBST) & 0 & $797.00 \pm 273.72$ & $38.17 \pm 4.79$ & $118.00 \pm 19.68$ & $147.00 \pm 22.62$ & $47.67 \pm 1.75$ & $15.17 \pm 1.83$ \\
\hline \multirow[t]{3}{*}{ p-MWCNTs } & 0.02 & $914.00 \pm 206.90$ & $40.50 \pm 1.00$ & $136.00 \pm 2.65$ & $166.00 \pm 10.30 *$ & $50.75 \pm 1.29$ & $14.50 \pm 1.50$ \\
\hline & 0.1 & $687.50 \pm 50.66$ & $38.83 \pm 11.86$ & $127.67 \pm 2 \mid .52$ & $164.33 \pm 9.22 *$ & $49.83 \pm 2.14$ & $15.50 \pm 0.55$ \\
\hline & 0.5 & $791.60 \pm 256.94$ & $62.8 \pm 29.98^{*}$ & $195.00 \pm 29.81 *$ & $169.00 \pm 12.43^{*}$ & $49.40 \pm 1.67$ & $15.40 \pm 1.82$ \\
\hline MWCNTs-PEG & 0.1 & $933.50 \pm 278.47$ & $43.67 \pm 8.8$ & $167.67 \pm 45.37 *$ & $164.00 \pm 14.04^{*}$ & $49.67 \pm 2.50$ & $15.17 \pm 1.47$ \\
\hline
\end{tabular}

Note: $* P<0.05$ compared to control.

Abbreviations: p-MWCNTs, pristine multi-walled carbon nanotubes; MWCNTs-PEG, PEGylated multi-walled carbon nanotubes; LDH, lactate dehydrogenase; ALT, alanine aminotransferase; AST, aspartate aminotransferase; ALP, alkaline phosphatase; TP, total protein; ALB, albumin; PBST, phosphate buffer containing $0.5 \%$ Tween-80. 
Table 4 Clinical chemistry of mice after 28 days of intravenous treatment with p-MWCNTs and MWCNTs-PEG

\begin{tabular}{lllllll}
\hline Group & Dose $(\mathbf{m g} / \mathbf{k g} \cdot \mathbf{b w})$ & TG $(\mathbf{m m o l} / \mathbf{L})$ & CHOL $(\mathbf{m m o l} / \mathbf{L})$ & GLU (mmol/L) & BUN (mmol/L) & CRE (mmol/L) \\
\hline Control (PBST) & 0 & $1.96 \pm 0.29$ & $3.59 \pm 0.98$ & $6.70 \pm 1.65$ & $5.48 \pm 0.55$ & $24.00 \pm 10.14$ \\
P-MWCNTs & 0.02 & $1.87 \pm 0.52$ & $4.38 \pm 0.89$ & $6.63 \pm 1.05$ & $5.15 \pm 1.67$ & $29.50 \pm 0.96$ \\
& 0.1 & $2.01 \pm 0.72$ & $4.11 \pm 0.64$ & $7.75 \pm 1.12$ & $6.07 \pm 0.93$ & $29.00 \pm 2.53$ \\
& 0.5 & $2.15 \pm 0.42$ & $3.95 \pm 0.62$ & $7.40 \pm 1.28$ & $5.68 \pm 0.72$ & $31.60 \pm 4.16$ \\
MWCNTs-PEG & 0.1 & $1.71 \pm 0.97$ & $3.86 \pm 0.90$ & $8.13 \pm 3.47$ & $5.37 \pm 1.34$ & $29.00 \pm 3.10$ \\
\hline
\end{tabular}

Abbreviations: p-MWCNTs, pristine multi-walled carbon nanotubes; MWCNTs-PEG, PEGylated multi-walled carbon nanotubes; TG, triglyceride; CHOL, cholesterol; GLU, glucose; BUN, urea nitrogen; CRE, creatinine; PBST, phosphate buffer containing $0.5 \%$ Tween- 80 .

splenocyte proliferation when compared with the negative control group $(P<0.05)$. In the MWCNTs-PEG group, HC50 and ConA-induced splenocyte proliferation were slightly decreased compared with the negative control group, but it was not significant (Table 6). There was no obvious difference in the NK cell activity among the four groups. The results suggest that high concentrations of p-MWCNTs may have the potential effect on mice humoral and cellular immune function.

\section{Discussion}

\section{Comparison of observed immune toxicity with other studies}

MWCNTs show great potential for biomedical applications, including delivery of bioactive molecules, targeted cancer therapy, and biological imaging. Some studies have shown that PEG has many advantages, such as good hydrophilicity, high flexibility, antiphagocytosis against macrophages, resistance to immunological recognition, non-combination with proteins, minimize immune responses, and biocompatibility. ${ }^{35}$ However, comparatively the potential adverse effect of pristine and PEG-modified MWCNTs on biological systems, specifically the immune system, is currently not well understood and needs further research.

The first indication for a toxic effect of the intravenously administered p-MWCNTs and MWCNTs-PEG was the observed enlarged brownish colored lungs, spleens, and livers and enlarged and dark colored lymph nodes in mice of the $0.5 \mathrm{mg} / \mathrm{kg} \cdot \mathrm{bw}$ of $\mathrm{p}$-MWCNTs group. A significant increase in organ coefficient was observed (Figure 3). Spleen weight with a dose of $0.02-0.5 \mathrm{mg} / \mathrm{kg} \cdot \mathrm{bw}$ and thymus weight around $0.5 \mathrm{mg} / \mathrm{kg} \cdot \mathrm{bw}$ were the most sensitive general toxicity parameters for p-MWCNTs toxicity. Also, for the liver and lung, a significant weight increase was observed. In previous studies, after acute and subchronic intratracheal instillation with $0.04,0.2$, or $1 \mathrm{mg} / \mathrm{kg}$ of MWCNT suspension, no obvious increase in the lung weight and body weight was observed in any of the MWCNT-exposed groups. ${ }^{36}$ Also, in a 2-week and 4-week toxicity study in rats conducted by the same research group, there were no effect on body and minimal effects on lung weight changes after MWCNT aerosol exposures. ${ }^{37} \mathrm{How}-$ ever, in ICR mice, the intraperitoneal administration of 10 , 50 , or $250 \mathrm{mg} / \mathrm{kg}$ body weight of phosphorylcholine-grafted MWCNTs (MWCNTs-PC) daily did result in a significantly lowering of body weight in mice of the high-dose group, and tissue to body weight ratios of liver, spleen, and lung rose significantly with an increasing dose of MWCNT-PC. ${ }^{29}$ In our study, we used the intravenous route by passing the need for crossing cellular barriers in the lung and gastrointestinal tract (GI) tract to evaluate possible systemic toxic effects of p-MWCNTs and MWCNTs-PEG. So, the whole dose administered was systemically available and the internal exposure (as presented by the intravenous dose) resulting in toxic responses could be identified. ${ }^{38}$

Table 5 Lymphocyte subpopulations of mice after 28 days of intravenous treatment with p-MWCNTs and MWCNTs-PEG

\begin{tabular}{llllllll}
\hline Group & Dose (mg/kg.bw) & T-cell (CD3 $)$ & B-cell (CD 19 $)$ & NK $\left(C D 49+^{+}\right.$ & CD4 $^{+}$ & CD8 $^{+}$ & CD4 $^{+}$CD8 $^{+}$ \\
\hline Control (PBST) & 0 & $52.06 \pm 5.47$ & $31.58 \pm 8.87$ & $15.73 \pm 2.72$ & $40.23 \pm 4.43$ & $10.56 \pm 2.25$ & $3.95 \pm 0.88$ \\
P-MWCNTs & 0.02 & $57.45 \pm 16.30$ & $29.25 \pm 5.72$ & $14.30 \pm 1.77$ & $46.06 \pm 5.22$ & $9.64 \pm 5.22$ & $5.26 \pm 1.51$ \\
& 0.1 & $46.6 \pm 14.50$ & $35.33 \pm 13.24$ & $17.04 \pm 5.50$ & $34.24 \pm 3.31^{*}$ & $11.08 \pm 3.31$ & $4.11 \pm 0.77$ \\
& 0.5 & $41.22 \pm 16.23^{*}$ & $23.37 \pm 8.54^{*}$ & $17.25 \pm 8.54$ & $27.09 \pm 3.20^{*}$ & $9.87 \pm 3.20$ & $3.03 \pm 0.17^{*}$ \\
MWCNTs-PEG & 0.1 & $48.79 \pm 19.01$ & $26.92 \pm 8.87$ & $15.42 \pm 2.83$ & $37.76 \pm 5.5$ & $10.31 \pm 3.84$ & $3.60 \pm 0.9 I^{*}$ \\
\hline
\end{tabular}

Note: $* P<0.05$ compared to control.

Abbreviations: p-MWCNTs, pristine multi-walled carbon nanotubes; MWCNTs-PEG, PEGylated multi-walled carbon nanotubes; NK, natural killer; PBST, phosphate buffer containing $0.5 \%$ Tween- 80 . 

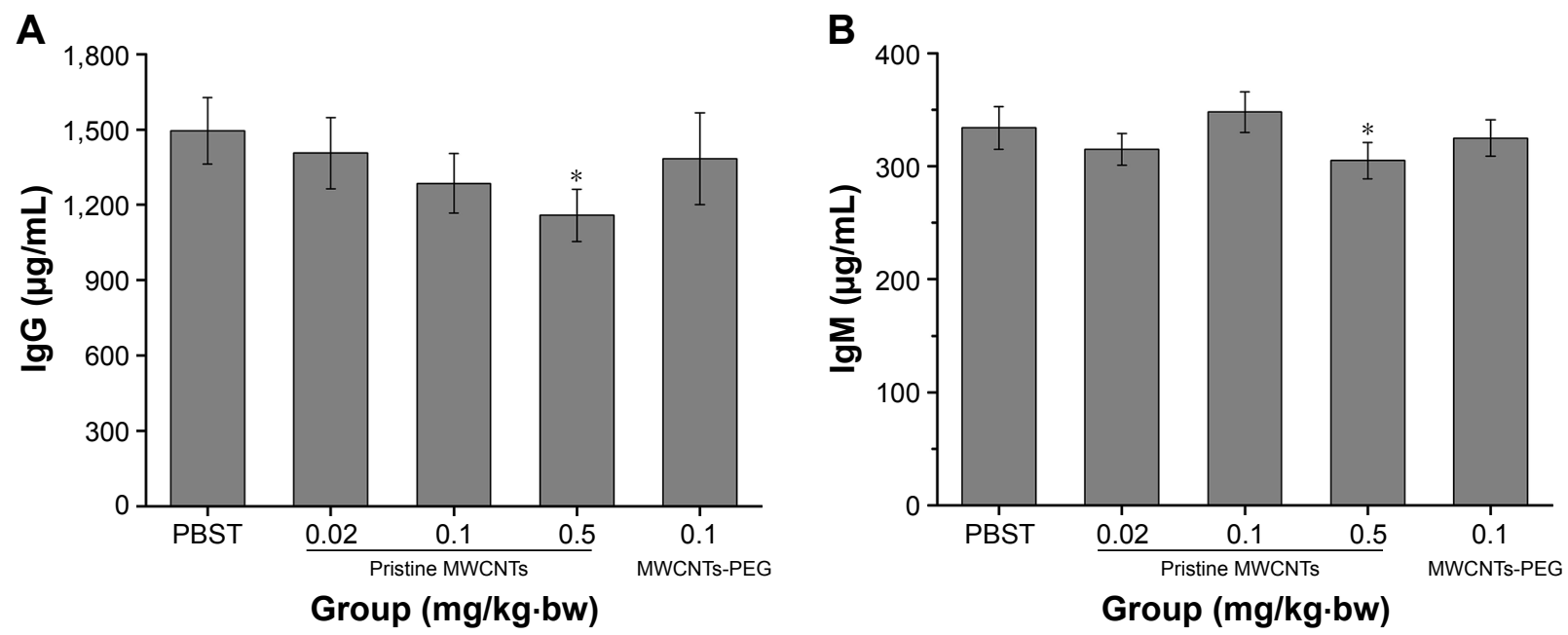

Figure 6 Effects of p-MWCNTs and MWCNTs-PEG on the secretion of $\lg (\mathbf{A})$ and $\lg M(\mathbf{B})$ in the serum.

Notes: Data represent the mean $\pm S D$ of six mice. *Values significantly different from control results $(P<0.05)$.

Abbreviations: SD, standard deviation; MWCNTs, multi-walled carbon nanotubes; MWCNTs-PEG, PEGylated multi-walled carbon nanotubes; PBST, phosphate buffer containing $0.5 \%$ Tween- 80 .

Histopathological examination of the tissues indicated that p-MWCNT treatment could induce different degrees of damage in the lung, liver, and tail vein of the injection site, but no pathological changes were observed in spleen and lymph nodes of mice in the treated groups. It was remarkable that the accumulation of the MWCNTs in Kupffer cells was accompanied by an inflammatory reaction in the liver. Also, in the lungs, the presence of MWCNTs was accompanied by an inflammatory response. Meanwhile, in the tail vein of the injection areas, a granulomatous inflammation could be identified. These granulomatous inflammatory reactions were partly caused by the injection technique as indicated by the presence of foreign body material in the inflammation and partly by the p-MWCNTs as indicated by the presence of granular pigment in the inflammation (Figure 4). Such granulomatous inflammation is a common side effect of prolonged repeated intravenous administrations, as with every injection there is a chance of injecting some skin and/or hair material in the circulation.
The increase of neutrophilic granulocytes in the blood does indicate an inflammatory response of the body (Table 2). Yet in the various other organs investigated, no indications for an inflammation could be observed. In previous instillation studies, histopathological changes and inflammatory reactions were observed only in the local area, including the lungs and lung-associated lymph nodes, and not in the other tissues. Transient pulmonary inflammatory responses were observed only in the lungs of the group of rats exposed to $1 \mathrm{mg} / \mathrm{kg}$ of MWCNTs. ${ }^{36}$ However, a 90-day intravenously exposed study in mice found SWCNTs in liver, lung, and spleen sections, and no obvious hepatic damage was observed in the histopathological study among all the exposed groups. ${ }^{39}$ It is remarkable that we observed splenocyte mitochondria swelling, irregular shape of nucleus, and chromatin condensation. It was found that the p-MWCNTs can enter the cell and bind to the mitochondria, which ultimately can induce structural changes of the mitochondria and subsequent effects.

Table 6 Effects of MWCNTs on immune function assays of mice

\begin{tabular}{|c|c|c|c|c|c|c|}
\hline Group & Dose (mg/kg.bw) & PFC $/ 10^{6}$ cells & HC50 & $\begin{array}{l}\text { LPS-induced splenocyte } \\
\text { proliferation }\end{array}$ & $\begin{array}{l}\text { ConA-induced splenocyte } \\
\text { proliferation }\end{array}$ & NK cell activity \\
\hline Control (PBST) & 0 & $85.39 \pm 15.95$ & $52.55 \pm 4.01$ & $2.57 \pm 0.24$ & $2.57 \pm 0.24$ & $20.37 \pm 2.01$ \\
\hline \multirow[t]{3}{*}{ p-MWCNTs } & 0.02 & $79.38 \pm 20.03$ & $40.38 \pm 3.36^{*}$ & $2.48 \pm 0.37$ & $2.38 \pm 0.26$ & $19.38 \pm 1.09$ \\
\hline & 0.1 & $76.35 \pm 23.56$ & $36.62 \pm 4.58^{*}$ & $2.55 \pm 0.83$ & $2.15 \pm 0.24$ & $17.35 \pm 2.03$ \\
\hline & 0.5 & $67.62 \pm 15.96 *$ & $39.45 \pm 5.16^{*}$ & $2.25 \pm 0.53 *$ & $1.85 \pm 0.31 *$ & $17.95 \pm 2.76$ \\
\hline MWCNTs-PEG & 0.1 & $80.52 \pm 16.86$ & $42.84 \pm 5.25$ & $2.38 \pm 0.65$ & $2.08 \pm 0.28$ & $18.64 \pm 2.15$ \\
\hline
\end{tabular}

Note: $* P<0.05$ compared to control.

Abbreviations: MWCNTs, multi-walled carbon nanotubes; PFC, plaque-forming cells; HC50, half value of hemolysis; LPS, lipopolysaccharides; NK, natural killer; PBST, phosphate buffer containing 0.5\% Tween-80; p-MWCNTs, pristine multi-walled carbon nanotubes; MWCNTs-PEG, multi-walled carbon nanotubes-polyethylene glycol. 
While there are no lymphatic vessels in the spleen, and the spleen is a blood-rich organ, we speculated that the systemic immunotoxicity of the MWCNTs to the spleen can be made only through the blood. Our results on clinical chemistry and hematology differ from the inhalation studies as in both inhalation studies no consistent alterations were seen in the clinical chemistry of the blood and cellular blood parameters, whereas we observed a dose-related effect for several clinical chemistry parameters. These differences may be due to the actual internal dose being higher in our studies to which organs such as liver, spleen, and bone marrow were exposed. In the blood, an effect was noted on the peripheral total WBC count and differential WBC (eosinophil, neutrophil, basophil, lymphocyte, and monocyte) counts. The alterations of WBC count may indicate that the MWCNTs induced the secretion of chemokines and raised the specific WBCs in the inflammatory area. A 90-day intravenously exposed study in mice found liver toxicity as indicated by an increase in serum biochemical parameters (LDH, ALT, and AST), which are important indicators of the hepatic injury. ${ }^{39}$ Similarly, we found an increase in these liver enzyme levels in serum of p-MWCNTs. However, although the presence of p-MWCNTs could be observed in the liver Kupffer cells, alterations indicating liver histopathology were not observed.

As an additional measure of immunotoxicity, we examined the effects of MWCNTs on serum IgG and IgM levels. After exposure to a xenobiotic, IgM is the first antibody to be made by the body to fight an infection, and IgG is the most abundant of the classes of immunoglobulins and plays a dominant role in humoral immunity. ${ }^{40}$ In the present study, after administration of $0.5 \mathrm{mg} / \mathrm{kg} \cdot \mathrm{bw}$ of p-MWCNTs, the levels of IgG and IgM significantly changed compared with control groups, which suggest that p-MWCNTs disordered the humoral immune function. However, MWCNTs-PEG did not elicit any IgM or IgG responses after either injection at $0.5 \mathrm{mg} / \mathrm{kg} \cdot \mathrm{bw}$. Taken together, these results show that p-MWCNTs can induce an antibody response depending on physicochemical characteristics of nanotubes.

With regard to the immune parameters, the changes in T-lymphocyte population and $\mathrm{CD} 4^{+} / \mathrm{CD}^{+}$ratios are generally recognized as the index of immune function. After the mice were intravenously administered p-MWCNTs and MWCNTs-PEG, no obvious histopathological changes were observed, and it can therefore be argued whether immune function is biologically significant. As shown in Table 6, the T-lymphocyte percentages of $\mathrm{CD}^{+}, \mathrm{CD}^{+}$, and $\mathrm{CD} 8^{+}$of $0.5 \mathrm{mg} / \mathrm{kg} \cdot \mathrm{bw}$ of p-MWCNTs were significantly decreased, and the $\mathrm{CD} 4^{+} / \mathrm{CD}^{+}$ratio was significantly increased compared with the control group. These results demonstrated that the T-lymphocyte level in the mice of the high-dose p-MWCNT group was significantly changed by the immunosuppressant; it is therefore possible that the presence of p-MWCNTs may damage immune function of mice.

In addition to common toxicological endpoints such as organ weight, blood clinical chemistry and hematology, and histopathology, immune toxicity in our previous study indicated spleen was one of the main target organs after an intravenous administration with MWCNTs. ${ }^{28}$ In this study, p-MWCNTs can cause a significant decrease in the number of lymph node cells producing immunoglobulins against SRBCs. Meanwhile, the lymphoproliferative response to ConA, a T-cell mitogen, was depressed at $0.5 \mathrm{mg} / \mathrm{kg} \cdot \mathrm{bw}$ of p-MWCNTs, and the response to the B-cell mitogen LPS was impaired in the same treated group. However, the innate immune response, as measured by NK activity, was not affected by any of MWCNTs. In p-MWCNT-treated mice, activated antigen-presenting cells (dendritic cells and macrophages) catch, engulf, and process injected SRBCs. They then migrate to spleen and lymph nodes, where they present antigenic molecules from the SRBCs to T lymphocytes, which in turn trigger immunoglobulin production of B cells.

\section{Physicochemical characteristic dependency of effects/relationship between the characteristics of nanoparticles and their toxic effects}

It is worth to note that the physicochemical particle characteristics are responsible for the different immune responses of the p-MWCNTs and MWCNTs-PEG. Shape is one of the important factors that determine the toxicity of CNTs. In previous studies, the longer needle-like CNTs showed higher toxicity than the shorter CNTs. The reason for this is that the longer MWCNTs allow for higher residential time in tissues and organs and induce stronger inflammation than shorter MWCNTs. ${ }^{41,42}$ In our present study, we hypothesized that the tube length of MWCNTs and functionalized surface play a role in the immune effects of MWCNTs. The length of p-MWCNTs became short in the process of functionalization, and treatment of mice with the longer MWCNTs caused significant immune response, while no detectable defects were evident after treatment with the shorter MWCNTs. A possible explanation is that increasing the diameter increases the bioactivity and induces significant immune response, which is consistent with previous studies showing that longer MWCNT are more bioactive ${ }^{43}$ Studies have also shown that degree of agglomeration, ${ }^{26,44,45}$ charge, ${ }^{46}$ surface chemical modification, ${ }^{47}$ and metal contaminants ${ }^{48}$ could affect 
CNT toxicity in vivo or in vitro. Comparing with f-MWCNT, more inflammation occurred in the p-MWCNTs. Owing to the modified CNTs being highly water-soluble and having a low agglomeration, they were taken up into the cells without decreasing cell viability. Chemically functionalized CNTs are generally considered to be low cytotoxic and have higher biocompatibility and low toxicity, especially when functionalized with PEG. A possible hypothesis is that PEGylation prevents proteins adsorption onto CNTs and reduces its immunogenicity, and hence reduces the interaction between CNTs and biosystem. PEG-modified nanomaterials can be applied to biomedicine because of their biosafety. ${ }^{49}$ Our previous studies have shown that MWCNTs-PEG showed low cytotoxicity, less inflammation, and good biocompatibility in macrophages. ${ }^{34}$ By contrast, the cytotoxicity of p-MWCNTs has been found to increase in a dose-dependent manner. Furthermore, p-MWCNTs have been reported to produce membrane damage, ROS generation, and inflammation significantly than MWCNTs-PEG. Similarly, in the present study, MWCNTs-PEG did not alter splenocyte proliferation, spleen weight, and serum IgG/IgM levels and specific immunity. By contrast, we now present data indicating that p-MWCNTs may cause more damage to the immunological function and the dysregulation of the spleen than MWCNTs-PEG. In other words, p-MWCNTs produced significant immunotoxicity than MWCNTs-PEG at the same dose. Although the relation between immune toxicity and characterizations is not completely clear, several of the mentioned characteristics may also influence the immune cells to antigen recognition processing and change transmission potential of CNTs.

\section{Conclusion}

We compared systemic and immunotoxicity of p-MWCNTs and MWCNTs-PEG in mice to examine the effects of modification of MWCNTs. Mice treated with p-MWCNTs induced increases in spleen, thymus, and lung weight, altered lymphocyte populations (CD3, CD4, CD8, and CD19) in peripheral blood and serum IgM and IgG levels. Morphological results show that lung and liver histological changes, local inflammatory reaction in the injection site, and splenic macrophages ultrastructure changes. Special immune function results showed that $\mathrm{p}-\mathrm{MWCNT}$ inhibited humoral and cellular immunity functions and were associated with decreased immune responses against sheep erythrocytes and serum hemolysis level. The results suggest that in vivo exposure to p-MWCNTs caused more damage to systemic immunity through the dysregulation of the spleen compared to MWCNTs-PEG. Understanding the immunotoxicity effects not only guides the rational design of biocompatible CNTs but also provides insights into how systemic immunotoxicity can be induced. Future research should employ this study's results to not only focus on the systemic immunotoxicity but also on special immune function changes, in order to develop better biological applicability of CNTs.

\section{Acknowledgments}

This work was supported by Natural Science Foundation of China (grant numbers 81673218, 81302461, 81473003 and, 31671034), Research Fund for the Doctoral Program of Higher Education (grant number 20130092120062), and the National Important Project on Scientific Research of China (grant number 2011CB933404).

\section{Author contributions}

TZ, SZ, and YH carried out the animal studies and performed the data and statistical analysis. TZ and YX drafted the manuscript. TZ and HL contributed to the preparation and characterization of the MWCNTs. MT coordinated the study, acquired funding, and helped writing the manuscript. YP coordinated and designed the study and wrote the final manuscript. All the authors read and approved the final manuscript. All authors contributed toward data analysis, drafting and critically revising the paper and agree to be accountable for all aspects of the work.

\section{Disclosure}

The authors report no conflicts of interest in this work.

\section{References}

1. Ajayan PM, Tour JM. Materials science: nanotube composites. Nature. 2007;447(7148):1066-1068.

2. Kostarelos K, Bianco A, Prato M. Promises, facts and challenges for carbon nanotubes in imaging and therapeutics. Nat Nanotechnol. 2009; 4(10):627-633.

3. Laverny G, Casset A, Purohit A, et al. Immunomodulatory properties of multi-walled carbon nanotubes in peripheral blood mononuclear cells from healthy subjects and allergic patients. Toxicol Lett. 2013; 217(2):91-101.

4. Wu HC, Chang X, Liu L, Zhao F, Zhao Y. Chemistry of carbon nanotubes in biomedical applications. J Mater Chem. 2010;20(6):1036-1052.

5. Tkach AV, Shurin GV, Shurin MR, et al. Direct effects of carbon nanotubes on dendritic cells induce immune suppression upon pulmonary exposure. ACS Nano. 2011;5(7):5755-5762.

6. Dobrovolskaia MA, McNeil SE. Immunological properties of engineered nanomaterials. Nat Nanotechnol. 2007;2(8):469-478.

7. Zolnik BS, González-Fernández Á, Sadrieh N, Dobrovolskaia MA. Nanoparticles and the immune system. Endocrinology. 2010;151(2): 458-465.

8. Pescatori M, Bedognetti D, Venturelli E, et al. Functionalized carbon nanotubes as immunomodulator systems. Biomaterials. 2013; 34(18):4395-4403.

9. Delogu LG, Venturelli E, Manetti R, et al. Ex vivo impact of functionalized carbon nanotubes on human immune cells. Nanomedicine (Lond). 2012; $7(2): 231-243$.

10. Sun Z, Liu Z, Meng J, et al. Carbon nanotubes enhance cytotoxicity mediated by human lymphocytes in vitro. PLoS One. 2011;6(6):e21073. 
11. Klaper R, Arndt D, Setyowati K, Chen J, Goetz F. Functionalization impacts the effects of carbon nanotubes on the immune system of rainbow trout, Oncorhynchus mykiss. Aquat Toxicol. 2010;100(2):211-217.

12. Dumortier H, Lacotte S, Pastorin G, et al. Functionalized carbon nanotubes are non-cytotoxic and preserve the functionality of primary immune cells. Nano Lett. 2006;6(7):1522-1528.

13. Palomäki J, Karisola P, Pylkkänen L, Savolainen K, Alenius H. Engineered nanomaterials cause cytotoxicity and activation on mouse antigen presenting cells. Toxicology. 2010;267(1-3):125-131.

14. Wang J, Sun RH, Zhang N, et al. Multi-walled carbon nanotubes do not impair immune functions of dendritic cells. Carbon. 2009;47(7): $1752-1760$.

15. Grecco AC, Paula RF, Mizutani E, et al. Up-regulation of T lymphocyte and antibody production by inflammatory cytokines released by macrophage exposure to multi-walled carbon nanotubes. Nanotechnology. 2011;22(26):265103.

16. Yamaguchi A, Fujitani T, Ohyama K, et al. Effects of sustained stimulation with multi-wall carbon nanotubes on immune and inflammatory responses in mice. J Toxicol Sci. 2012;37(1):177-189.

17. Park EJ, Cho WS, Jeong J, Yi J, Choi K, Park K. Pro-inflammatory and potential allergic responses resulting from $\mathrm{B}$ cell activation in mice treated with multi-walled carbon nanotubes by intratracheal instillation. Toxicology. 2009;259(3):113-121.

18. Mitchell LA, Gao J, Wal RV, Gigliotti A, Burchiel SW, McDonald JD. Pulmonary and systemic immune response to inhaled multiwalled carbon nanotubes. Toxicol Sci. 2007;100(1):203-214.

19. Mitchell LA, Lauer FT, Burchiel SW, McDonald JD. Mechanisms for how inhaled multiwalled carbon nanotubes suppress systemic immune function in mice. Nat Nanotechnol. 2009;4(7):451-456.

20. Cheng C, Müller KH, Koziol KK, et al. Toxicity and imaging of multiwalled carbon nanotubes in human macrophage cells. Biomaterials. 2009;30(25):4152-4160.

21. Bottini M, Rosato N, Bottini N. PEG-modified carbon nanotubes in biomedicine: current status and challenges ahead. Biomacromolecules. 2011;12(10):3381-3393.

22. Wang X, Xia T, Ntim SA, et al. Dispersal state of multiwalled carbon nanotubes elicits profibrogenic cellular responses that correlate with fibrogenesis biomarkers and fibrosis in the murine lung. ACS Nano. 2011;5(12):9772-9787.

23. Wang L, Luanpitpong S, Castranova V, et al. Carbon nanotubes induce malignant transformation and tumorigenesis of human lung epithelial cells. Nano Lett. 2011;11(7):2796-2803.

24. Wang X, Zang JJ, Wang H, et al. Pulmonary toxicity in mice exposed to low and medium doses of water-soluble multi-walled carbon nanotubes. J Nanosci Nanotechnol. 2010;10(12):8516-8526.

25. Hamilton RF Jr, Wu Z, Mitra S, Shaw PK, Holian A. Effect of MWCNT size, carboxylation, and purification on in vitro and in vivo toxicity, inflammation and lung pathology. Part Fibre Toxicol. 2013; 10(1):57.

26. Allegri M, Perivoliotis DK, Bianchi MG, et al. Toxicity determinants of multi-walled carbon nanotubes: the relationship between functionalization and agglomeration. Toxicol Rep. 2016;3:230-243.

27. Aldieri E, Fenoglio I, Cesano F, et al. The role of iron impurities in the toxic effects exerted by short multiwalled carbon nanotubes (MWCNT) in murine alveolar macrophages. $J$ Toxicol Environ Health A. 2013; 76(18):1056-1071.

28. Liang G, Zhang T, Liu R, Ye B, Yin L, Pu Y. Preparation and biodistribution of tyrosine modified multiwall carbon nanotubes. J Nanosci Nanotechnol. 2010;10(12):8508-8515.

29. Liang G, Yin L, Zhang J, et al. Effects of subchronic exposure to multi-walled carbon nanotubes on mice. $J$ Toxicol Environ Health A. 2010;73(7):463-470.
30. Zhang T, Tang M, Kong L, et al. Comparison of cytotoxic and inflammatory responses of pristine and functionalized multi-walled carbon nanotubes in RAW 264.7 mouse macrophages. $J$ Hazard Mater. 2012;219-220:203-212.

31. Ladics GS. Use of SRBC antibody responses for immunotoxicity testing. Methods. 2007;41(1):9-19.

32. Huang R, Zhao M, Yang X, et al. Effects of Prunella vulgaris on the mice immune function. PLoS One. 2013;8(10):e77355.

33. Costabile M. Measuring the $50 \%$ haemolytic complement ( $\mathrm{CH} 50)$ activity of serum. J Vis Exp. 2010;29(37):1923.

34. Zhang T, Tang M, Kong L, et al. Surface modification of multiwall carbon nanotubes determines the pro-inflammatory outcome in macrophage. J Hazard Mater. 2015;284:73-82.

35. Knop K, Hoogenboom R, Fischer D, Schubert US. Poly (ethylene glycol) in drug delivery: pros and cons as well as potential alternatives. Angew Chem Int Ed Engl. 2010;49(36):6288-6308.

36. Kobayashi N, Naya M, Ema M, et al. Biological response and morphological assessment of individually dispersed multi-wall carbon nanotubes in the lung after intratracheal instillation in rats. Toxicology. 2010;276(3):143-153.

37. Umeda Y, Kasai T, Saito M, et al. Two-week toxicity of multi-walled carbon nanotubes by whole-body inhalation exposure in rats. J Toxicol Pathol. 2013;26(2):131-140.

38. De Jong WH, Van Der Ven LT, Sleijffers A, et al. Systemic and immunotoxicity of silver nanoparticles in an intravenous 28 days repeated dose toxicity study in rats. Biomaterials. 2013;34(33): 8333-8343.

39. Yang ST, Wang X, Jia G, et al. Long-term accumulation and low toxicity of single-walled carbon nanotubes in intravenously exposed mice. Toxicol Lett. 2008;181(3):182-189.

40. Schroeder HW Jr, Cavacini L. Structure and function of immunoglobulins. J Allergy Clin Immunol. 2010;125(2 Suppl 2):S41-S52.

41. Poland CA, Duffin R, Kinloch I, et al. Carbon nanotubes introduced into the abdominal cavity of mice show asbestos-like pathogenicity in a pilot study. Nat Nanotechnol. 2008;3(7):423-428.

42. Xu J, Alexander DB, Futakuchi M, et al. Size- and shape-dependent pleural translocation, deposition, fibrogenesis, and mesothelial proliferation by multiwalled carbon nanotubes. Cancer Sci. 2014;105(7):763-769.

43. Donaldson K, Murphy FA, Duffin R, Poland CA. Asbestos, carbon nanotubes and the pleural mesothelium: a review of the hypothesis regarding the role of long fibre retention in the parietal pleura, inflammation and mesothelioma. Part Fibre Toxicol. 2010;7:5.

44. Lacerda L, Ali-Boucetta H, Herrero MA, et al. Tissue histology and physiology following intravenous administration of different types of functionalized multiwalled carbon nanotubes. Nanomedicine (Lond). 2008;3(2):149-161.

45. Murray AR, Kisin ER, Tkach AV, et al. Factoring-in agglomeration of carbon nanotubes and nanofibers for better prediction of their toxicity versus asbestos. Part Fibre Toxicol. 2012;9:10.

46. Li R, Wang X, Ji Z, et al. Surface charge and cellular processing of covalently functionalized multiwall carbon nanotubes determine pulmonary toxicity. ACS Nano. 2013;7(3):2352-2368.

47. Bussy C, Pinault M, Cambedouzou J, et al. Critical role of surface chemical modifications induced by length shortening on multi-walled carbon nanotubes-induced toxicity. Part Fibre Toxicol. 2012;9:46.

48. Ge C, Li Y, Yin JJ, et al. The contributions of metal impurities and tube structure to the toxicity of carbon nanotube materials. NPG Asia Mater. 2012;4:e32.

49. Schipper ML, Nakayama-Ratchford N, Davis CR, et al. A pilot toxicology study of single-walled carbon nanotubes in a small sample of mice. Nat Nanotechnol. 2008;3(4):216-221. 


\section{Supplementary materials}

\section{Method}

\section{Characterization of MWCNTs}

The samples (pristine multi-walled carbon nanotubes [p-MWCNTs], carboxyl-functionalized multi-walled carbon nanotubes, and PEGylated multi-walled carbon nanotubes [MWCNTs-PEG]) were characterized by Fourier transform infrared spectroscopy (FTIR; PerkinElmer, Waltham, MA, USA), and validated with thermogravimetric analysis (TGA; PE Pyris1 TGE; PerkinElmer), inductively coupled plasma mass spectrometry (J-A1100; Jarrell-Ash, Waltham, MA, USA), and transmission electron microscopy (JEM-2100; JEOL, Tokyo, Japan).

\section{Results}

\section{FTIR spectroscopy}

Figure S1 shows the FTIR spectra of pristine and functionalized multi-walled carbon nanotubes (f-MWCNTs). For the former, the FTIR spectra exhibited a straight line and an absorbance peak was not assigned, indicating no surface modification. For the MWCNTs-PEG spectra, the $2,920 \mathrm{~cm}^{-1}$ peak could be assigned to the methylene groups and the $1,100 \mathrm{~cm}^{-1}$ peak to the $\mathrm{C}-\mathrm{O}-\mathrm{C}$ vibration. The absorbance bands at $1,570,1,450,1,400$, and $1,240 \mathrm{~cm}^{-1}$ are consistent with PEG absorbance, strongly suggesting the existence of PEG-MWCNTs. The absorbance at $1,730 \mathrm{~cm}^{-1}$ is typically associated with ester groups and indicates a chemical linkage between MWCNTs and PEG segments.

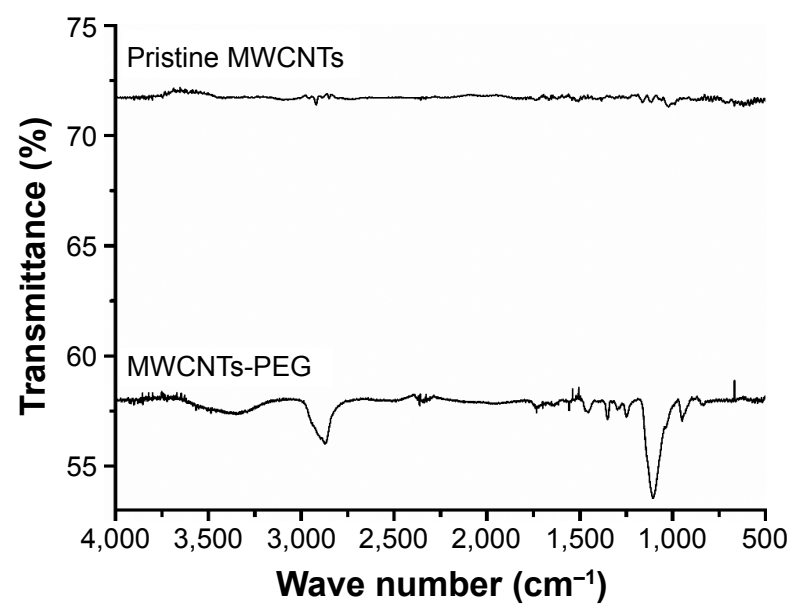

Figure SI FTIR spectra of MWCNTs in reflectance mode.

Abbreviations: FTIR, Fourier transform infrared spectroscopy; MWCNTs, multi-walled carbon nanotubes; MWCNTs-PEG, PEGylated multi-walled carbon nanotubes.

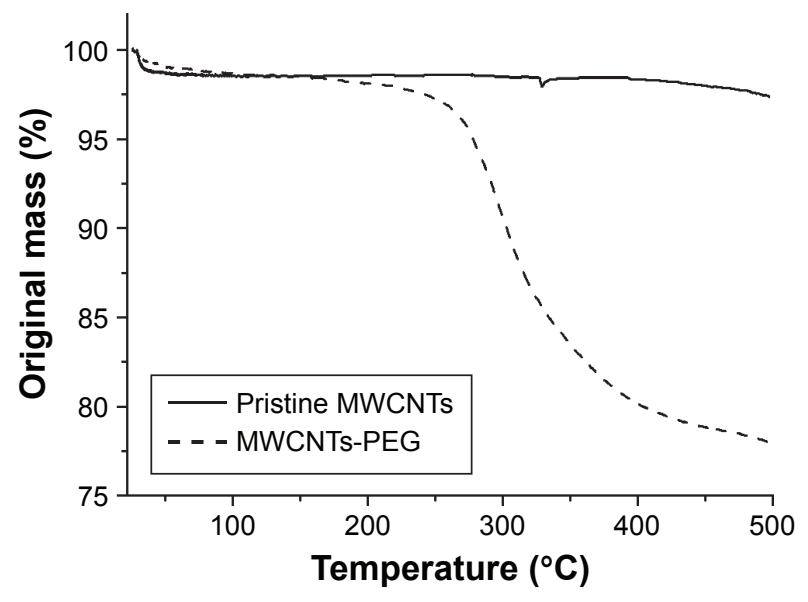

Figure S2 TGA curves of MWCNTs in nitrogen atmosphere.

Abbreviations: TGA, thermogravimetric analysis; MWCNTs, multi-walled carbon nanotubes; MWCNTs-PEG, PEGylated multi-walled carbon nanotubes.

\section{TGA}

TGA is used to monitor how changes in manufacturing conditions affect the percentage of carbon nanotubes within a sample. On heating up to $500^{\circ} \mathrm{C}$, p-MWCNTs lost about $1.3 \%$ of total weight (Figure S2). MWCNTs-PEG lost 19.4\% weight. Therefore, about $20 \mathrm{wt} \%$ of side groups were grafted onto MWCNTs, indicating that the difference in properties between pristine and modified MWCNTs arose from these side moieties.

Table SI Dose levels and experimental design of 28 days of repeated dose toxicity study with MWCNTs

\begin{tabular}{ll}
\hline Treatment & Dose $(\mathbf{m g} / \mathbf{k g} \cdot \mathbf{b w}$ per week) \\
\hline Control (PBST) & 0 \\
P-MWCNTs & 0.02 \\
& 0.1 \\
MWCNTs & 0.5 \\
\end{tabular}

Abbreviations: MWCNTs, multi-walled carbon nanotubes; PBST, phosphate buffer containing $0.5 \%$ Tween-80; p-MWCNTs, pristine multi-walled carbon nanotubes. 
Table S2 Body weight of mice after 28 days of intravenous treatment with p-MWCNTs and MWCNTs-PEG

\begin{tabular}{lllllll}
\hline Group & Dose $(\mathbf{m g} / \mathbf{k g} \cdot \mathbf{b w})$ & Initial body weight & $\mathbf{7}$ days & I4 days & $\mathbf{2 1}$ days & $\mathbf{2 8}$ days \\
\hline Control (PBST) & 0 & $20.48 \pm 0.64$ & $22.62 \pm 1.35$ & $22.19 \pm 1.29$ & $22.97 \pm 0.65$ & $25.02 \pm 2.19$ \\
P-MWCNTs & 0.02 & $20.92 \pm 1.25$ & $23.57 \pm 1.89$ & $22.45 \pm 0.88$ & $23.78 \pm 0.95$ & $26.74 \pm 3.45$ \\
& 0.1 & $20.16 \pm 1.25$ & $22.18 \pm 1.14$ & $24.44 \pm 2.38$ & $24.68 \pm 1.98$ & $26.11 \pm 2.14$ \\
& 0.5 & $20.01 \pm 0.84$ & $20.56 \pm 0.74$ & $22.36 \pm 1.25$ & $23.58 \pm 1.12$ & $26.78 \pm 3.03$ \\
MWCNTs-PEG & 0.1 & $20.56 \pm 0.74$ & $21.94 \pm 0.87$ & $22.19 \pm 0.81$ & $23.53 \pm 0.72$ & $25.33 \pm 3.14$ \\
\hline
\end{tabular}

Abbreviations: PBST, phosphate buffer containing 0.5\% Tween-80; p-MWCNTs, pristine multi-walled carbon nanotubes; MWCNTs-PEG, PEGylated multi-walled carbon nanotubes.

\section{Publish your work in this journal}

The International Journal of Nanomedicine is an international, peerreviewed journal focusing on the application of nanotechnology in diagnostics, therapeutics, and drug delivery systems throughout the biomedical field. This journal is indexed on PubMed Central, MedLine, CAS, SciSearch ${ }^{\circledR}$, Current Contents ${ }^{\circledR} /$ Clinical Medicine,
Journal Citation Reports/Science Edition, EMBase, Scopus and the Elsevier Bibliographic databases. The manuscript management system is completely online and includes a very quick and fair peer-review system, which is all easy to use. Visit http://www.dovepress.com/ testimonials.php to read real quotes from published authors. 